\title{
Augmentation of cognitive function in epilepsy
}

\author{
Thomas B. DeMarse ${ }^{1 *}$ and Paul R. Carney ${ }^{1,2 *}$ \\ 1 J. Crayton Pruitt Family Department of Biomedical Engineering, University of Florida, Gainesville, FL, USA \\ 2 Department of Pediatrics, University of Florida, Gainesville, FL, USA \\ *Correspondence: tdemarse@bme.ufl.edu; carnepr@peds.ufl.edu
}

\section{Edited by:}

Mikhail Lebedev, Duke University, USA

Reviewed by:

Höller Yvonne, Paracelsus Medical University Salzburg, Austria

Marta Parazzini, Consiglio Nazionale delle Ricerche, Italy

Keywords: non-invasive brain stimulation, tDCS, memory, cognition, epilepsy

Epilepsy is one of the most common neurological disorders in humans afflicting more than $1 \%$ of the population and 65 million people worldwide (England et al., 2012). The most common form of acquired epilepsy is temporal lobe epilepsy (TLE), and over $30 \%$ of patients with TLE have seizures that are refractory to commonly used anticonvulsant drugs (Bauer and Burr, 2001). Mesial temporal lobe sclerosis (MTS) is the most common pathological abnormality in TLE (Bronen et al., 1997). The histopathological hallmarks of hippocampal sclerosis include segmental loss of pyramidal neurons, granule cell dispersion, and reactive gliosis (Sutula et al., 1989). Indeed, changes in the integrity of hippocampus and surrounding hippocampal white matter is postulated to influence overall temporal lobe network connectivity, hippocampus efficiency, seizures (Cadotte et al., 2009), and memory function (Eichenbaum et al., 2007, 2012). Indeed, animal and human studies show that abnormalities in the hippocampus and its white matter inputs and outputs are correlated with the severity of memory dysfunction (Christidi et al., 2011).

\section{TEMPORAL LOBE CONNECTIVITY IN TLE: FILLING GAPS IN KNOWLEDGE}

Patterned inputs to the hippocampus from mediobasal cortical regions and entrorhinal cortex are hypothesized to support critical memory functions of recollection (controlled, deliberate recall) and familiarity (automatic, item-based memory), respectively (Eichenbaum and Lipton, 2008; Eichenbaum et al., 2012; Dixon et al., 2014). An integrated theory of parahippocampal (PHc), perirhinal (PRc), entrorhinal (ERc), and hippocampal (HC) functioning [the 'Binding of Items and Context [BIC] Model (Diana et al., 2007)], suggests that these structures form an integrated circuit that supports recollection and familiarity. The PRc is proposed to be important in encoding and retrieving items (e.g., objects, words, and ideas), whereas the $\mathrm{PHc}$ is responsible for representing spatial, temporal, and semantic context. The HC supports memory for episodes by integrating these inputs and binding the item-based contextual information together as a unique event in space and time. In this view, the formation of new memories depends upon the integrated series of inputs from PRc and PHc components of the parahippocampal gyrus and their respective targets in the ERc and hippocampus. Despite extensive animal work, it is unknown in humans whether selective damage to these areas or their interconnections that produce subtypes of memory impairment might differentially respond to different types of memory training. Although some data exists on the efficacy of memory rehabilitation programs, little is known about the neural basis of individualized rehabilitation responses from a mechanistic perspective (Wagner, 2011).

\section{IMPLICATIONS FOR MEMORY REHABILITATION}

Understanding individual differences in morphological and connectional components of medial temporal lobe injury in TLE can lead to identification of subtypes of memory impairment, and thus help identify clinically important targets for memory augmentation. Our hypothesis is that the subtypes of memory impairment that result will preferentially respond to specific memory interventions, a notion that is also being addressed in the aphasia treatment literature (Kim et al., 2011). To this end, an emerging method for treating neurologically-induced memory impairment is non-invasive brain stimulation (NIBS), including transcranial direct current stimulation (tDCS) and transcranial magnetic stimulation (TMS). Both tDCS and TMS are safe for use in human subjects (Nitsche et al., 2003b), and have been used widely to test hypothesis about causal links between specific brain structures supporting cognition and memory (Dayan et al., 2013; Hummel, 2014). Indeed, several studies support the use of NIBS techniques as tools for enhancing cognitive function in normal subjects and as therapeutic agents for individuals with psychiatric and neurologic disorders (Hummel and Cohen, 2006; Miniussi et al., 2008). NIBS consist of applying a weak (0.5-2.0 mA in tDCS) direct current through the scalp and skull. Depending on the polarity of the current during stimulation, NIBS may increase or decrease the rate of neuronal firing by modulating the resting membrane potentials (Creutzfeldt et al., 1962; Bindman et al., 1964; Liebetanz et al., 2002; Nitsche et al., 2003a; Zaghi et al., 2010). Although these studies are preliminary, they do provide reassuring proof-of-principle that the stimulated brain region is part of a critical circuit for performing the task under investigation.

The application of brain stimulation in combination with specific memory 
rehabilitation methods (Stringer and Small, 2011) has been put forth as a strategy to compensate for basic defects in TLE-related memory processing (Miatton et al., 2011; Sankar et al., 2012; Suthana et al., 2012; Fell et al., 2013; Hariz et al., 2013; Hartikainen et al., 2014; Suthana and Fried, 2014). These studies demonstrate that electrical neuromodulation of specific deep structures within the medial temporal lobe may have persistent benefits in memory function.

NIBS has been shown to significantly decrease seizures in individuals with treatment-resistant epilepsy (Fregni et al., 2006; Nitsche and Paulus, 2009; San-Juan et al., 2011; Varga et al., 2011; Yook et al., 2011; Auvichayapat et al., 2013; Parazzini et al., 2014). Whether NIBS techniques can also improve memory function in TLE is an area of much interest. To this end, recent reports suggest that NIBS may augment cognition in a wide array of neurologic and psychiatric disorders, including schizophrenia (Minzenberg and Carter, 2012), Alzheimer's disease (Boggio et al., 2006), depression (Brunoni et al., 2012), and post-stroke recovery (Floel, 2014). Although the underlying mechanism that produces the cognitive deficits associated with epilepsy may differ from those that produce similar deficits in other disorders, the mechanism that enables tDCS' therapeutic effect appears to transcend individual disease. These results strongly suggest that tDCS may represent an excellent potential new treatment modality for epilepsy. Therefore, future studies on the possible effects of tDCS in TLE are highly warranted. There are however, a number of significant issues that must be addressed for tDCS to become practical as a treatment for TLE.

\section{FUTURE DIRECTIONS}

While NIBS has been shown to be relatively safe, currently there is surprisingly little known about the specific mechanisms underlying the therapeutic effects (Reato et al., 2013). Nevertheless, various postulates have been put forward such as $\mathrm{N}$-methyl-D-aspartate receptor mediated long and short-term potentiation modulation (Liebetanz et al., 2002; Nitsche et al., 2004; Thickbroom and Mastaglia, 2009). Studies aimed at defining the dose for NIBS techniques in space and in time, as well as determining the safe stimulation intensity parameters and electrode positions, are now critical to propel this field forward. Finally, with regard to tDCS, it was initially believed to primarily affect cortical regions directly beneath the electrode. However, there are now a number of reports based on results from computer modeling suggesting that the current during tDCS may in fact reach deeper areas, such as the hippocampus (Sadleir et al., 2010; Parazzini et al., 2012). In order to systemically reach the hippocampus and surrounding structures at therapeutic levels, computer modeling will be needed and will likely play an increasingly important role in the design of electrode montages that can consistently reach these areas in the future. Fortunately, a number of groups now use computer modeling to gain a better understanding of where current is flowing during NIBS as well as methods to guide or focus current (Datta et al., 2009; Bai et al., 2013; Dmochowski et al., 2013; Edwards et al., 2013). While NIBS techniques offer the capability to modulate large or diverse areas of the brain, it is still an open question as to what extent electrical neuromodulation in one brain area may affect adjacent or more distant areas and mechanism of action. However, recent efforts are beginning to explore these many complex issues directly (Keeser et al., 2011; Polania et al., 2011; Lamy et al., 2012; Polania et al., 2012; Park et al., 2013; Hampstead et al., 2014; Notturno et al., 2014).

Future advancements in current methodologies for NIBS may provide substantial improvements during focal delivery of stimulation to the temporal lobe for memory augmentation. Also, improvements in multi-modal noninvasive techniques such as fMRI or MEG, may be able to detect neural signatures reflective of NIBS related neurophysiological changes within the hippocampus and surrounding structures that result in memory enhancement. Through the combined use of NIBS and multiunit local field potential recordings in combination with non-invasive measurements such as EEG and fMRI studies we may be able to optimize detection and determine the precise neuronal correlates of NIBS related behavioral changes. Other training techniques such as neurofeedback may also allow patients the ability to modulate electrical stimulation oscillatory activity in order to achieve improvements in memory.

In summary, it will become increasingly important for future studies to build upon and elucidate the mechanism of action used in NIBS enhancement of memory. The location, parameters, and phase of delivery of NIBS may need to vary amongst individuals. Hence, systematic comparisons and consistent methodologies across studies will likely contribute to a solid understanding of NIBS and its effects on learning and memory. Resolution of these issues may be crucial as to whether NIBS based therapeutics will advance toward a useful treatment for patients with TLE related memory problems.

\section{REFERENCES}

Auvichayapat, N., Rotenberg, A., Gersner, R., Ngodklang, S., Tiamkao, S., Tassaneeyakul, W., et al. (2013). Transcranial direct current stimulation for treatment of refractory childhood focal epilepsy. Brain Stimul. 6, 696-700. doi: 10.1016/j. brs.2013.01.009

Bai, S., Loo, C., and Dokos, S. (2013). A review of computational models of transcranial electrical stimulation. Crit. Rev. Biomed. Eng. 41, 21-35. doi: 10.1615/CritRevBiomedEng.2013007163

Bauer, J., and Burr, W. (2001). Course of chronic focal epilepsy resistant to anticonvulsant treatment. Seizure 10, 239-246. doi: 10.1053/seiz.2000.0499

Bindman, L. J., Lippold, O. C., and Redfearn, J. W. (1964). Relation between the size and form of potentials evoked by sensory stimulation and the background electrical activity in the cerebral cortex of the rat. J. Physiol. 171, 1-25.

Boggio, P. S., Ferrucci, R., Rigonatti, S. P., Covre, P., Nitsche, M., Pascual-Leone, A., et al. (2006). Effects of transcranial direct current stimulation on working memory in patients with Parkinson's disease. J. Neurol. Sci. 249, 31-38. doi 10.1016/j.jns.2006.05.062

Bronen, R. A., Fulbright, R. K., King, D., Kim, J. H., Spencer, S. S., Spencer, D. D., et al. (1997) Qualitative MR imaging of refractory temporal lobe epilepsy requiring surgery, correlation with pathology and seizure outcome after surgery. Am. J. Roentgenol. 169, 875-882. doi: 10.2214/ajr.169.3. 9275915

Brunoni, A. R., Ferrucci, R., Fregni, F., Boggio, P. S., and Priori, A. (2012). Transcranial direct current stimulation for the treatment of major depressive disorder, a summary of preclinical, clinical and translational findings. Prog. Neuropsychopharmacol. Biol. Psychiatry 39, 9-16. doi: 10.1016/j.pnpbp.2012.05.016

Cadotte, A. J., Mareci, T. H., DeMarse, T. B., Parekh, M. B., Rajagovindan, R., Ditto, W. L., et al. (2009) Temporal lobe epilepsy, anatomical and effective connectivity. IEEE Trans. Neural Syst. Rehabil. Eng. 17, 214-223. doi: 10.1109/TNSRE.2008. 2006220 
Christidi, F., Bigler, E. D., McCauley, S. R., Schnelle, K. P., Merkley, T. L., Mors, M. B., et al. (2011). Diffusion tensor imaging of the perforant pathway zone and its relation to memory function in patients with severe traumatic brain injury. J. Neurotrauma 28, 711-725. doi: 10.1089/neu. 2010.1644

Creutzfeldt, O. D., Fromm, G. H., and Kapp, H. (1962). Influence of transcortical d-c currents on cortical neuronal activity. Exp. Neurol. 5, 436-452. doi: 10.1016/0014-4886(62)90056-0

Datta, A., Bansal, V., Diaz, J., Patel, J., Reato, D., and Bikson, M. (2009). Gyri-precise head model of transcranial direct current stimulation, improved spatial focality using a ring electrode versus conventional rectangular pad. Brain Stimul. 2, 201-207, 207, e201. doi: 10.1016/j.brs.2009.03.005

Dayan, E., Censor, N., Buch, E. R., Sandrini, M., and Cohen, L. G. (2013). Noninvasive brain stimulation, from physiology to network dynamics and back. Nat. Neurosci. 16, 838-844. doi: $10.1038 / \mathrm{nn} .3422$

Diana, R. A., Yonelinas, A. P., and Ranganath, C. (2007). Imaging recollection and familiarity in the medial temporal lobe, a three-component model. Trends Cogn. Sci. 11, 379-386. doi: 10.1016/j.tics. 2007.08.001

Dixon, M. L., Fox, K. C., and Christoff, K. (2014). Evidence for rostro-caudal functional organization in multiple brain areas related to goal-directed behavior. Brain Res. 1572, 26-39. doi: 10.1016/j. brainres.2014.05.012

Dmochowski, J. P., Datta, A., Huang, Y., Richardson, J. D., Bikson, M., Fridriksson, J., et al. (2013). Targeted transcranial direct current stimulation for rehabilitation after stroke. Neuroimage 75 , 12-19. doi: 10.1016/j.neuroimage.2013.02.049

Edwards, D., Cortes, M., Datta, A., Minhas, P. Wassermann, E. M., and Bikson, M. (2013). Physiological and modeling evidence for focal transcranial electrical brain stimulation in humans: a basis for high-definition tDCS. Neuroimage 74, 266-275. doi: 10.1016/j. neuroimage.2013.01.042

Eichenbaum, H., and Lipton, P. A. (2008). Towards a functional organization of the medial temporal lobe memory system: role of the parahippocampal and medial entorhinal cortical areas. Hippocampus 18, 1314-1324. doi: 10.1002/hipo.20500

Eichenbaum, H., Sauvage, M., Fortin, N., Komorowski, R., and Lipton, P. (2012). Towards a functional organization of episodic memory in the medial temporal lobe. Neurosci. Biobehav. Rev. 36, 1597-1608. doi: 10.1016/j.neubiorev.2011.07.006

Eichenbaum, H., Yonelinas, A. P., and Ranganath, C. (2007). The medial temporal lobe and recognition memory. Annu. Rev. Neurosci. 30, 123-152. doi: 10.1146/annurev.neuro.30.051606.094328

England, M. J., Liverman, C. T., Schultz, A. M., and Strawbridge, L. M. (2012). Epilepsy across the spectrum: promoting health and understanding. a summary of the institute of medicine report. Epilepsy Behav. 25, 266-276. doi: 10.1016/j.yebeh.2012.06.016

Fell, J., Staresina, B. P., Do Lam, A. T., Widman, G., Helmstaedter, C., Elger, C. E., et al. (2013). Memory modulation by weak synchronous deep brain stimulation: a pilot study. Brain Stimul. 6, 270-273. doi: 10.1016/j.brs.2012.08.001
Floel, A. (2014). tDCS-enhanced motor and cognitive function in neurological diseases. Neuroimage 85( $\mathrm{Pt}$ 3), 934-947. doi: 10.1016/j.neuroimage. 2013.05.098

Fregni, F., Thome-Souza, S., Nitsche, M. A. Freedman, S. D., Valente, K. D., and PascualLeone, A. (2006). A controlled clinical trial of cathodal DC polarization in patients with refractory epilepsy. Epilepsia 47, 335-342. doi: 10.1111/j.1528-1167.2006.00426.x

Hampstead, B. M., Brown, G. S., and Hartley, J. F. (2014). Transcranial direct current stimulation modulates activation and effective connectivity during spatial navigation. Brain Stimul. 7, 314-324. doi: 10.1016/j.brs.2013. 12.006

Hariz, M., Blomstedt, P., and Zrinzo, L. (2013). Future of brain stimulation: new targets, new indications, new technology. Mov. Disord. 28, 1784-1792. doi: $10.1002 / \mathrm{mds} .25665$

Hartikainen, K. M., Sun, L., Polvivaara, M., Brause, M., Lehtimaki, K., Haapasalo, J., et al. (2014). Immediate effects of deep brain stimulation of anterior thalamic nuclei on executive functions and emotion-attention interaction in humans. J. Clin. Exp. Neuropsychol. 36, 540-550. doi 10.1080/13803395.2014.913554

Hummel, F. C. (2014). [Combination of TMS and MRT to understand neurological diseases]. Nervenarzt 85, 708-713. doi: 10.1007/s00115-0133997-z

Hummel, F. C., and Cohen, L. G. (2006). Non-invasive brain stimulation: a new strategy to improve neurorehabilitation after stroke? Lancet Neurol. 5, 708-712. doi: 10.1016/S1474-4422(06)70525-7

Keeser, D., Meindl, T., Bor, J., Palm, U., Pogarell, O., Mulert, C., et al. (2011). Prefrontal transcranial direct current stimulation changes connectivity of resting-state networks during fMRI. J. Neurosci. 31, 15284-15293. doi: 10.1523/JNEUROSCI.054211.2011

Kim, E. S., Rapcsak, S. Z., Andersen, S., and Beeson, P. M. (2011). Multimodal alexia: neuropsychological mechanisms and implications for treatment. Neuropsychologia 49, 3551-3562. doi: 10.1016/j.neuropsychologia.2011.09.007

Lamy, J. C., Badel, A., Arrigo, R. T., and Boakye, M. (2012). Dynamic modulation of intrinsic functional connectivity by transcranial direct current stimulation. J. Neurophysiol. 108, 3253-3263. doi: 10.1152/jn.00606.2012

Liebetanz, D., Nitsche, M. A., Tergau, F., and Paulus, W. (2002). Pharmacological approach to the mechanisms of transcranial DC-stimulationinduced after-effects of human motor cortex excitability. Brain 125(Pt 10), 2238-2247. doi: 10.1093/brain/awf238

Miatton, M., Van Roost, D., Thiery, E., Carrette, E., Van Dycke, A., Vonck, K., et al. (2011). The cognitive effects of amygdalohippocampal deep brain stimulation in patients with temporal lobe epilepsy. Epilepsy Behav. 22, 759-764. doi: 10.1016/j.yebeh.2011.09.016

Miniussi, C., Cappa, S. F., Cohen, L. G., Floel, A., Fregni, F., Nitsche, M. A., et al. (2008). Efficacy of repetitive transcranial magnetic stimulation/transcranial direct current stimulation in cognitive neurorehabilitation. Brain Stimul. 1, 326-336. doi: 10.1016/j.brs.2008.07.002
Minzenberg, M. J., and Carter, C. S. (2012). Developing treatments for impaired cognition in schizophrenia. Trends Cogn. Sci. 16, 35-42. doi: 10.1016/j.tics.2011.11.017

Nitsche, M. A., Jaussi, W., Liebetanz, D., Lang, N., Tergau, F., and Paulus, W. (2004). Consolidation of human motor cortical neuroplasticity by D-cycloserine. Neuropsychopharmacology 29, 1573-1578. doi: 10.1038/sj.npp.1300517

Nitsche, M. A., Liebetanz, D., Antal, A., Lang, N., Tergau, F., and Paulus, W. (2003a). Modulation of cortical excitability by weak direct current stimulation-technical, safety and functional aspects. Suppl. Clin. Neurophysiol. 56, 255-276. doi: 10.1016/S1567-424X(09)70230-2

Nitsche, M. A., Liebetanz, D., Lang, N., Antal, A., Tergau, F., and Paulus, W. (2003b). Safety criteria for transcranial direct current stimulation (tDCS) in humans. Clin. Neurophysiol. 114, 2220-2222; author reply 2222-2223. doi: 10.1016/S1388-2457(03) 00235-9

Nitsche, M. A., and Paulus, W. (2009). Noninvasive brain stimulation protocols in the treatment of epilepsy: current state and perspectives. Neurotherapeutics 6, 244-250. doi: 10.1016/j.nurt.2009.01.003

Notturno, F., Marzetti, L., Pizzella, V., Uncini, A., and Zappasodi, F. (2014). Transcranial direct current stimulation modulates activation and effective connectivity during spatial navigation. Hum. Brain Mapp. 35, 2220-2232. doi: 10.1002/hbm. 22322

Parazzini, M., Fiocchi, S., Liorni, I., Priori, A., and Ravazzani, P. (2014). Computational modeling of transcranial direct current stimulation in the child brain: implications for the treatment of refractory childhood focal epilepsy. Int. J. Neural Syst. 24:1430006. doi: 10.1142/S012906571430006X

Parazzini, M., Fiocchi, S., and Ravazzani, P. (2012). Electric field and current density distribution in an anatomical head model during transcranial direct current stimulation for tinnitus treatment. Bioelectromagnetics 33, 476-487. doi: 10.1002/bem.21708

Park, C. H., Chang, W. H., Park, J. Y., Shin, Y., Kim, S. T., and Kim, Y. H. (2013). Transcranial direct current stimulation increases resting state interhemispheric connectivity. Neurosci. Lett. 539, 7-10. doi: 10.1016/j.neulet.2013.01.047

Polania, R., Nitsche, M. A., and Paulus, W. (2011). Modulating functional connectivity patterns and topological functional organization of the human brain with transcranial direct current stimulation. Hum. Brain Mapp. 32, 1236-1249. doi: 10.1002/hbm.21104

Polania, R., Paulus, W., and Nitsche, M. A. (2012). Modulating cortico-striatal and thalamo-cortical functional connectivity with transcranial direct current stimulation. Hum. Brain Mapp. 33, 2499-2508. doi: 10.1002/hbm.21380

Reato, D., Rahman, A., Bikson, M., and Parra, L. C. (2013). Effects of weak transcranial alternating current stimulation on brain activity-a review of known mechanisms from animal studies. Front. Hum. Neurosci. 7:687. doi: 10.3389/fnhum.2013. 00687

Sadleir, R. J., Vannorsdall, T. D., Schretlen, D. J., and Gordon, B. (2010). Transcranial direct 
current stimulation (tDCS) in a realistic head model. Neuroimage 51, 1310-1318. doi: 10.1016/ j.neuroimage.2010.03.052

San-Juan, D., Calcaneo Jde, D., Gonzalez-Aragon, M. F., Bermudez Maldonado, L., Avellan, A. M., Argumosa, E. V., et al. (2011). Transcranial direct current stimulation in adolescent and adult Rasmussen's encephalitis. Epilepsy Behav. 20, 126-131. doi: 10.1016/j.yebeh.2010.10.031

Sankar, T., Tierney, T. S., and Hamani, C. (2012). Novel applications of deep brain stimulation. Surg. Neurol. Int. 3(Suppl. 1), S26-S33. doi: 10.4103/ 2152-7806.91607

Stringer, A. Y., and Small, S. K. (2011). Ecologicallyoriented neurorehabilitation of memory: robustness of outcome across diagnosis and severity. Brain Inj. 25, 169-178. doi: 10.3109/02699052. 2010.541894

Suthana, N., and Fried, I. (2014). Deep brain stimulation for enhancement of learning and memory. Neuroimage 85(Pt 3), 996-1002. doi: 10.1016/j. neuroimage.2013.07.066

Suthana, N., Haneef, Z., Stern, J., Mukamel, R., Behnke, E., Knowlton, B., et al. (2012). Memory enhancement and deep-brain stimulation of the entorhinal area. N. Engl. J. Med. 366, 502-510. doi: 10.1056/NEJMoal107212
Sutula, T., Cascino, G., Cavazos, J., Parada, I., and Ramirez, L. (1989). Mossy fiber synaptic reorganization in the epileptic human temporal lobe. Ann. Neurol. 26, 321-330. doi: 10.1002/ana.410260303

Thickbroom, G. W., and Mastaglia, F. L. (2009). Plasticity in neurological disorders and challenges for noninvasive brain stimulation (NBS). J. Neuroeng. Rehabil. 6, 4. doi: 10.1186/17430003-6-4

Varga, E. T., Terney, D., Atkins, M. D., Nikanorova, M., Jeppesen, D. S., Uldall, P., et al. (2011). Transcranial direct current stimulation in refractory continuous spikes and waves during slow sleep: a controlled study. Epilepsy Res. 97, 142-145. doi: 10.1016/j.eplepsyres.2011.07.016

Wagner, A. K. (2011). Rehabilomics: a conceptual framework to drive biologics research. $P M R$ 3(6 Suppl. 1), S28-S30. doi: 10.1016/j.pmrj.2011. 04.013

Yook, S. W., Park, S. H., Seo, J. H., Kim, S. J., and Ko, M. H. (2011). Suppression of seizure by cathodal transcranial direct current stimulation in an epileptic patient-a case report. Ann. Rehabil. Med. 35, 579-582. doi: 10.5535/arm.2011.35. 4.579

Zaghi, S., Acar, M., Hultgren, B., Boggio, P. S., and Fregni, F. (2010). Noninvasive brain stimulation with low-intensity electrical currents: putative mechanisms of action for direct and alternating current stimulation. Neuroscientist 16, 285-307. doi: $10.1177 / 1073858409336227$

Conflict of Interest Statement: The authors declare that the research was conducted in the absence of any commercial or financial relationships that could be construed as a potential conflict of interest.

Received: 12 June 2014; accepted: 29 July 2014; published online: 14 August 2014.

Citation: DeMarse TB and Carney PR (2014) Augmentation of cognitive function in epilepsy. Front. Syst. Neurosci. 8:147. doi: 10.3389/fnsys.2014.00147

This article was submitted to the journal Frontiers in Systems Neuroscience.

Copyright (C) 2014 DeMarse and Carney. This is an open-access article distributed under the terms of the Creative Commons Attribution License (CC BY). The use, distribution or reproduction in other forums is permitted, provided the original author(s) or licensor are credited and that the original publication in this journal is cited, in accordance with accepted academic practice. No use, distribution or reproduction is permitted which does not comply with these terms. 